\begin{tabular}{|l|l|l|l|}
\hline Eiszeitalter u. Gegenwart & $\mathbf{2 7}$ & $\begin{array}{c}26-29 \\
1 \mathrm{Abb} .\end{array}$ & Öhringen/Württ. 1976 \\
\hline
\end{tabular}

\title{
Erste Hinweise auf eine pliozäne Donau in der östlichen Iller-Lech-Platte (Bayerisch Schwaben) *)
}

\author{
(Vorläufige Mitteilung)
}

\section{LORENZ SCHEUENPFLUG $*$ )}

Key words: Germany, Swabia, Iller-Lech-Platte, Danube, Pliocene, early Pleistocene, old watershed, petrography of gravels

K u r zf a ssung: Funde nicht-alpiner Gerölle südlich des altpleistozänen Donaulaufs in deı östlichen Iller-Lech-Platte werden als umgelagerte Reste pliozäner Donauschotter gedeutet und geben so erste Hinweise auf ein Ausgreifen der Donau 35-40 km südlich ihres heutigen Laufs. Die bisher als Tertiärrelikt angesehene Dinkelscherbener Altwasserscheide dieses Bereichs kann somit erst im Pleistozän entstanden sein und dürfte kaum am Staufenberg vorbei weiter nach NNO gereicht haben.

[First references to a pliocene Danube in the eastern Iller-Lech-Platte (Germany, Swabia)]

A b s t r a c t : Rounded stones of non-alpine origin, found in the south of the early pleistocene Danube current in the eastern Iller-Lech-Platte (plateau) are assumed to be displaced last remnants of gravel deposits, accumulated by a pliocene Danube. They give first references to her current about 35 or $40 \mathrm{~km}$ more southern. The Dinkelscherbener Altwasserscheide (old watershed), till now regarded as a tertiary remnant, can be formed not earlier than in the pleistocene and probably must not be elongated beyond the Staufenberg to NNE.

\section{Das Gebiet}

In der östlichen Iller-Lech-Platte zwischen Mindel und Lech werden im groben drei ältest- oder altpleistozäne Lager fluvioglazialer Schotter unterschieden:

1) Das Staufenberggebiet (Bibereiszeit, SCHAEFER 1957).

2) Die Staudenplatte (Donaueiszeit, Eberl 1930; Schaefer 1953, 1957).

3) Die Zusamplatte (Günzeiszeit, Schaefer 1957; Donaueiszeitengruppe, Löscher 1974, 1976).

Staufenberggebiet und Staudenplatte sind von der Zusamplatte durch die Dinkelscherbener Altwasserscheide (GRAul 1949) getrennt, die größtenteils im Verlauf des Pleistozäns beseitigt und teilweise durch Reliefumkehr in Beckenlandschaften verwandelt worden ist. Graul (1949: 5) sieht sie als „das alte Wasserscheidengelände zwischen dem Mindel-Iller-Abflußnetz im W und dem Wertach-Lech-System im E“ an, spricht sich aber schriftlich nicht über den Beginn ihres Bestehens und ihrer Funktion aus. Den Staufenberg zählt er zur Altwasserscheide. Erst Schaefer (1957: 31) gibt zeitliche Hinweise: „Diese Wasserscheide ist eines der ältesten und wichtigsten paläogeographischen Elemente des bayerisch-württembergischen Alpenvorlandes. Sie war schon vorhanden, als nach Abschluß der mio-pliozänen Geosynklinal-Sedimentation des Alpenvorlandes, von ihr durch einen scharfen (Erosions-)Schnitt getrennt, die plio-pleistozäne Diluvial-Akkumulation einsetzte, deren ältester Zeuge der Staufenbergschotter (nordwestlich Augsburg) ist." Beweise

*) Dieses Thema wurde kurz im Rahmen eines Vortrags auf der 18. Tagung der Deutschen Quartärvereinigung in Hamburg am 1. Sept. 1976 behandelt.

**) Anschrift des Verfassers: Lorenz S che ue n pflug, Keimstraße 7 c, 8901 NeusäßLohwald. 
dafür sind nicht angeführt. Weiterhin erklärt er (1957: 32): „Zu keiner Zeit konnte Donauwasser in das Gebiet (südöstlich der Altwasserscheide) gelangen. “ Löscher (1974, 1976) sieht die Altwasserscheide ebenfalls als Tertiärrelikt an und hält den Staufenberg für einen überschotterten Teil derselben. Er verfolgt ihren Zug weiter nach SW und W. Gerade weil der Staufenberg überschottert ist, kann er nach Meinung des Verfassers nicht als Altwasserscheide angesehen werden!

In der Zusamplatte ist die Südgrenze eines altpleistozänen Donaulaufes (bis zu $18 \mathrm{~km}$ südlich des rezenten) nachgewiesen worden (Scheuenpflug 1971), auf den Löscher (1974, 1976) näher eingeht.

\section{Funde}

Beim Untersuchen und regelmäßigen Beobachten aller sich bietenden Aufschlüsse, insbesondere bei qualitativen und quantitativen Schotteranalysen, fielen ganz vereinzelt $\mathrm{Ge}-$ rölle auf, deren Herkunft von Süc'en aus den Alpen oder den vorgelagerten Geröllfächern der Molasse nicht nachgewiesen werden konnte oder ganz ausschied ${ }^{1}$ ). Diese Gerölle lagen gleichermaßen in Solifluktionsdecken, periglazial-fluviatilen und fluvioglazialen Schottern. Es sind dieselben Gesteine, die von den altpleistozänen bis in die rezenten Donauablagerungen immer wieder ganz vereinzelt auftreten. Unter ihnen fallen besonders auf:

1) Schwarzwälder Buntsandstein,

2) rötlicher Schwarzwälder Granit (Eisenbach-Granit),

3) hellroter Schwarzwälder Porphyr,

4) gepreßter Quarzit,

5) Glimmerquarzit.

Die Herkunft der beiden letzten Gesteine schreibt Manz (1934) dem Einzugsgebiet der Ur-Aare zu, die während bestimmter Zeiten des Pliozäns den Oberlauf der Donau gebildet hat. Bis die Quarzite und überhaupt alle hier untersuchten Gerölle an ihre jetzigen Fundstellen gelangten, dürften sie mehrfach umgelagert worden sein. Für die Herkunft der faziesfremden Gerölle im Nordteil der Zusamplatte gilt die altpleistozäne Donau als erwiesen, deshalb werden sie im folgenden für diesen Bereich nicht weiter berücksichtigt.

\section{Deutungen}

Aus den Funden kann gefolgert werden: Diese Gerölle sind die umgelagerten letzten Reste aus den Schotterabsätzen einer pliozänen Donau, die durch Erosion und Solifluktion während des Pleistozäns an die heutigen Fundorte gelangten. Die im Verlauf des ganzen Quartärs wirkende Ausräumung ließ in diesem Gebiet keinen Flecken einer präquartären Landoberfläche übrig. Die zeitliche Ansprache ergibt sich aus der Fundhöhe der umgelagerten Gerölle und ihrem Vorkommen in den ältestpleistozänen, relativ höchstliegenden Staufenbergschottern.

Die Verbreitung der Funde (Abb. 1) deutet erstmalig im groben ein weites Ausgreifen der pliozänen Donau nach Süden an. Dabei dürften Werte erreicht worden sein, die zwischen Günzburg und Donauwörth etwa $35-40 \mathrm{~km}$ südlich des heutigen Flußlaufes reichen. Das Fundgebiet der Gerölle erstreckt sich weit über die Dinkelscherbener Altwasserscheide hinaus nach Süden und Südosten. Wegen möglicher tektonischer Einflüsse kann vorerst kein stratigraphischer Bezug zu den einschlägigen nächstliegenden Resten pliozäner Donauschotter am Rande der Schwäbischen Alb auf dem Eselsberg bei Ulm hergestellt werden.

1) Erste Hinweise auf diese Problematik verdanke ich Herrn Dr. S. S c h i e m e n z, München. 


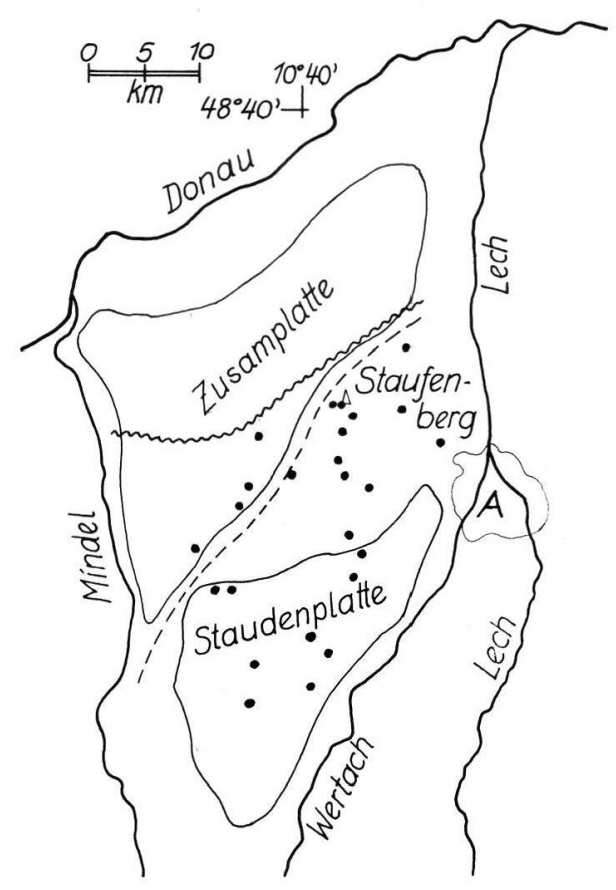

Abb. 1: Punkte: Fundorte der 34 Donaugerölle (mancher Punkt gilt für 2-3 Gesteine). Wellenlinie: Südgrenze des altpleistozänen Donaulaufs in der Zusamplatte. Gestrichelt: Dinkelscherbener Altwasserscheide (nach Graul 1949). A = Augsburg.

Das Vorkommen Schwarzwälder Buntsandsteine unter diesen Streufunden endet am Nordrand der Staudenplatte. Ob dies ein reiner Zufall ist oder auf einen faziellen Wechsel in der ursprünglichen Akkumulation deutet, bleibt unklar.

Aus diesen Annahmen ergeben sich paläogeographische Schlüsse: Die als Tertiärrelikt angesehene Dinkelscherbener Altwasserscheide kann in diesem Raum erst im Quartär entstanden und wirksam geworden sein, als die pliozäne Donau ihren Lauf weiter nach Norden verlegt hatte. Somit ist diese Altwasserscheide nur als Rest eines von der Flußerosion verschont gebliebenen alten Höhenrückens („Riedel“!) zwischen zwei Flüssen oder Flußsystemen anzusehen, dessen jüngere Verwandte noch heute das Landschaftsbild der IllerLech-Platte prägen. Die Dinkelscherbener Altwasserscheide läßt sich erstmals zeitgleich mit dem Entstehen der Staudenplatte indirekt nachweisen, als schätzungsweise die erste Hälfte des gesamten Pleistozäns schon vorüber gewesen ist. Unter diesem Blickpunkt ist auch die Herkunft der auf Restkuppen dieser und anderer Altwasserscheiden immer wieder anzutreffenden Geröllstreu leichter zu erklären. Auch einige der hier ausgewerteten Gerölle entstammen solchen Fundorten.

Innerhalb des Quartärs erscheint ein Verlängern der Altwasserscheide westlich am Staufenberg vorbei nach NNO nur als reine Annahme, solange der geographische Verlauf und das Zusammenspiel der ältestpleistozänen Donau, Iller, des Lechs und eventueller Flüsse aus dem periglaziären Bereich der östlichen Iller-Lech-Platte v o r dem Absatz der Staudenplattenschotter in völligem Dunkel liegen. Hier können sich vielleicht durch verfeinerte und erweiterte Untersuchungsmethoden der Quartärforscher an der Universität Köln neue Gesichtspunkte ergeben. 
Nur am Rande sei für zukünftige Arbeiten, die sich mit der Donau dieses Raumes befassen, an die Einflüsse des ältestpleistozänen Alpenrheins, ihres bedeutendsten Nebenflusses, erinnert, der den Wasserhaushalt und das Geröllspektrum der Donau wesentlich beeinflußt haben dürfte und der bisher in Schriftum sehr spärlich oder gar nicht beachtet worden ist.

D a n k : Herzlichen Dank schuldet der Verfasser den Herren Dr. Hermann J e r z, München, und Dr. Manfred L ösch er, Heidelberg, für die enge Zusammenarbeit; den Herren Willi Paul, Vöhrenbach (Schwarzwald), Udo Scholz, Kempten (Allgäu), und Karl Guckert, Blaichach (Allgäu), für viele Hinweise und das Bestimmen der Gesteine; dem Bayerischen Geologischen Landesamt, München, für den Dünnschliff und das Bestimmen eines rötlichen Granitgerölls.

Anmerkung: Die fraglichen Gesteine wurden außerdem mit der petrographischen Sammlung im Fürstlich Fürstenbergischen Schloß in Donaueschingen verglichen.

\section{Schriftenverzeichnis}

EberL, B. (1930): Die Eiszeitenfolge im nördlichen Alpenvorlande. - VIII + 427 S., 19 Abb., 2 Tf., 1 Kt.; Augsburg.

Graul, H. (1949): Zur Gliederung des Altdiluviums zwischen Wertach-Lech und Flossach-Mindel. - Ber. Naturforsch. Ges. Augsburg, 2: 3-31, 2 Abb., 3 Tab.; Augsburg.

Löscher, M. (1974): Die präwürmzeitlichen Schotterablagerungen in der nördlichen Iller-LechPlatte. - X $+158+41$ S., 23 Abb., 7 Fot., 4 Kt., 15 Prof.; Heidelberg. - [Masch.Schr. Diss.]

- (1976): Die präwürmzeitlichen Schotterablagerungen in der nördlichen Iller-Lech-Platte. Heidelberger Geogr. Arb., 45: IX + 157 S., 26 Abb., 4 Tab., 8 Tf., 4 Kt., 11 Längs-, 6 Querprof.; Heidelberg.

Manz, O. (1934, 1935): Die Ur-Aare als Oberlauf und Gestalterin der pliozänen Oberen Donau. Hohenzollerische Jh., 1: 113-160; 2: 187-227, $18 \mathrm{Abb}$. — [Ohne Ortsangabe.]

SchatFer, I. (1953): Die donaueiszeitlichen Ablagerungen an Lech und Wertach. - Geologica Bavarica, 19: 13-64, 15 Abb.; München.

- (1957): Erläuterungen zur Geologischen Karte von Augsburg und Umgebung 1 : 50000 . 92 S., 4 Abb., 1 Kt., 2 Beil.; München (Bayer. Geol. L.-Amt).

Scheuenpflug, L. (1971): Ein alteiszeitlicher Donaulauf in der Zusamplatte (Bayerisch Schwaben). - Ber. Naturforsch. Ges. Augsburg, 27: 3-10, 2 Abb.; Augsburg. 